\title{
EASTWOOD SE SUBE AL RING \\ PARA DEFENDER LA EUTANASIA
}

\section{EASTWOOD STEPS INTO THE RING DEFENDING FOR EUTHANASIA}

\author{
AUTORA \\ Juan Enrique Gonzálvez Vallés: Periodista. Profesor de la Universidad Camilo José \\ Cela. Universidad Complutense de Madrid (España) \\ juanen2012@gmail.com
}

\section{CURRÍCULUM VITAE}

Doctorando en Ciencias de la Información, en el programa “Teoría, técnica y análisis cinematográfico", del departamento de Comunicación Audiovisual y Publicidad II (CAP 2), Facultad de Ciencias de la Información, Universidad Complutense de Madrid. Licenciado en Periodismo (2004). Sus líneas de investigación se centran en el análisis cinematográfico y en la búsqueda de los estilemas de autor. Miembro del grupo de investigación Concilium.

\section{RESUMEN}

Este artículo analiza la nueva mirada de Clint Eastwood al cine centrado en los deportes. La historia del entrenador y la boxeadora que, desde lo más bajo, va estableciendo una relación paterno filial que se extiende también a su carrera pugilística. En la búsqueda de las huellas de autor, el análisis se centra en los diferentes aspectos tanto narrativos como técnicos que permite incardinar a Eastwood dentro del grupo de los llamados autores clásicos. 


\section{PALABRAS CLAVE}

Eastwood - Boxeo - Eutanasia - Estilema

\section{ABSTRACT}

This article analyzes the new look of the film Clint Eastwood focused on sports. The story of the trainer and the boxer who, from the lowest, is establishing a parent-child relationship also extends to his boxing career. In the search for traces of the author, the analysis focuses on the different technical aspects of narrative and allowing Eastwood incardinate within the group of so-called classics.

\section{KEY WORDS}

Eastwood - Boxing - Euthanasia - Stylemes

\section{ÍNDICE}

1. Análisis cinematográfico.

2. Sinopsis.

3. Conclusión.

4. Bibliografía.

\section{Análisis cinematográfico.}

Hay, sin lugar a dudas, varios puntos de inflexión en la carrera de Clint Eastwood. Lo fue "Bird", lo fue "Sin Perdón" y ahora se volverá a producir con "Million Dollar 
Baby". Es cierto que la Academia de Hollywood le debía algo a Clint desde que no premió lo suficiente "Mystic River" por su coincidencia con la última entrega de la trilogía de "El Señor de los Anillos".

Pero no es menos cierto que Eastwood iba a poner muy fácil a los académicos el que premiaran su labor con una gran película. El californiano se encuentra con el libro de Jerry Boyd, "Rope Burns", y no duda en lanzarse en una peligrosa aventura.

Le encargará a Paul Haggis la adaptación del guión para llevarlo a la gran pantalla y lo hará con gran éxito. De hecho, ésta será una colaboración que se ampliará con sus dos siguientes películas: “Le envié el primer borrador del guión y dos semanas después ya había elegido todo el reparto. Le llamé y me dijo que le gustaría que le escribiese el guión de Flags of Our Fathers. Yo le respondí que sería un honor, pero que antes deberíamos hablar del guión de Million Dollar Baby, porque el que le había enviado era básicamente un borrador. Me respondió que ya estaba bien así, que éste era precisamente el que iba a filmar." 1

Todo estaba previsto para que empezara el rodaje puesto que el casting de actores se celebró con celeridad y precisión. Pero Eastwood se encontró con la reticencia de uno de sus compañeros de viaje habituales: la Warner Bros.

“Me dijeron que era una película de boxeo. Yo les respondí que no sólo era sobre boxeo, que se trataba de una historia sobre padres e hijas y de muchas cosas más. Al final me dijeron que sí, que la harían, pero que querían únicamente pagar por los derechos en Estados Unidos y que buscara otro socio para financiar la parte correspondiente al mercado internacional (...) El problema es que hago películas que nadie quiere hacer. Parece como si tuvieran miedo de ellas. Supongo que se debe a la época que estamos viviendo, donde lo único que interesa son los remakes de series

\footnotetext{
${ }^{1}$ COMAS, Ángel. Clint Eastwood. Tras las huellas de Harry. T\&B Editores. Pág. 273
} 
televisivas de los setenta. Debo reconocer que soy una persona pesimista, pero a veces me pregunto qué clase de cine se hará de aquí a diez años si seguimos así. Cuando yo era un adolescente, podías ir a ver 'El sargento York' o 'Los viajes de Sullivan', sin contar entrañables 'films' de serie B. Ahora sólo les interesa repetir el último éxito de moda. Si 'Los increíbles' triunfa, sólo quieres hacer 'Los dobles increíbles'. Yo trato de hacer películas para un público que quiere ver historias adultas, con personajes reales y complejos, que es un tipo de cine más orientado hacia el viejo estilo. En cierto sentido, 'Million Dollar Baby' podría ser una película sobre un tipo de los años cuarenta o cincuenta, de otra época." 2

El hecho de que la historia uniera el boxeo y la eutanasia hizo que los directivos de la productora no apostaran inicialmente por el proyecto. De hecho, sólo comercializaron los derechos en Estados Unidos y Clint tuvo que buscar un socio para la parte internacional.

Lakeshore se arriesgó con el proyecto y financió la mitad de los dieciocho millones que costó elaborar este film. Un presupuesto realmente bajo con un plan de rodaje que se ajustó a seis semanas y que recaudó más de 100 millones de dólares en salas. "Finalmente los ejecutivos de la productora tuvieron que disculparse con el cineasta por haber dudado de él. Adelantaron incluso el estreno de la película dos meses para que pudiese entrar en los Oscar."3

Las críticas no pudieron ser más dispares. En Europa fue aclamada unánimemente y recibió muchísimos parabienes. En Estados Unidos, sin embargo, no tuvo tanta fortuna. Si bien una parte la valoró positivamente, tuvo duras y encarnizadas críticas de la parte más conservadora de la sociedad estadounidense.

\footnotetext{
${ }^{2}$ COMAS, Ángel. Clint Eastwood. Tras las huellas de Harry. T\&B Editores. Pág. 274.

${ }^{3}$ SCHICKEL, Richard. Clint Eastwood: una retrospectiva. Editorial Blume. Pág. 250.
} 
Eastwood demostró una vez más su independencia ideológica y cinematográfica hacia estos comentarios reaccionarios: “Nunca pensé en la parte política al hacer el film. Quizá este alcanzando una edad en que empiece a estar senil o nostálgico, o ambas cosas a la vez, pero las personas ahora son muy irritables. Antes podías no estar de acuerdo con alguien y seguir siendo amigos. Ahora cada uno que piensa diferente de ti es subnormal o un idiota, tanto los de la derecha como los de la izquierda". 4

El hecho de que fuera premiada con cuatro Oscar de peso terminó por hacer vencer y convencer a Eastwood. Fue la gran ganadora de la ceremonia con su estatuilla a la mejor película, que redondeó una noche donde todos los personajes de la cinta fueron premiados de alguna manera.

Eastwood se llevó el premio al mejor director por segunda vez en su carrera. A nadie la hubiera extrañado que también se hubiera llevado el premio al mejor actor, que terminó recayendo en Jamie Foxx por "Ray". Aunque también es seguro que al californiano le llenó mucho más el que se le siga reconociendo más como autor, por encima incluso de su interpretación.

Aunque Hillary Swank se quedó también con la parte interpretativa de Eastwood: "Pienso que es su mejor actuación hasta la fecha. Resulta tan conmovedor en la película que sentí verdadero terror viendo esta parte de Clint tan avejentado, tan vulnerable pero tan valiente e incisivo." 5

Hillary Swank también fue reconocida por su papel de la chica del millón de dólares. La actriz estuvo inconmensurable como Maggie Fitzgerald con un registro sensacional para afrontar todos los estados de la truncada boxeadora. Como

\footnotetext{
${ }^{4}$ COMAS, Ángel. Clint Eastwood. Tras las huellas de Harry. T\&B Editores. Pág. 277

${ }^{5}$ COMAS, Ángel. Clint Eastwood. Tras las huellas de Harry. T\&B Editores. Pág. 277
} 
anécdota queda el que Swank ganara su segundo Oscar, tras "Boys Don't Cry" en su segunda nominación.

Eastwood quedó encantado con el trabajo de la actriz: "Hillary se preparó constantemente. Es una chica atlética con gran habilidad, pero también muy delgada, así que tuvimos que meterla en un programa de entrenamiento de pesos pesados. Boxeaba dos horas cada noche y hacía pesas dos horas cada mañana durante cuatro meses. Lucia Rijker, que interpreta al Oso Azul, es una gran campeona. Está hecha de acero, puede golpear a un animal, y fue de gran ayuda para Hilary en su entrenamiento." 6

Por último, Morgan Freeman recibió también un reconocimiento tan justo como pendiente. No había conseguido la estatuilla ni por "Paseando a Miss Daisy", ni por "Cadena Perpetua", ni por "Sin Perdón" y por fin recibió el dorado galardón. Su actuación se complementa con una narración en off que supone la última sorpresa de la película.

Eastwood decide darle un regalo final al espectador cuando descubre que las palabras de Freeman, es decir, Eddie Dupris, no son sólo una narración de los hechos. El fiel escudero de Frankie Dunn está implorando a la hija de éste que vuelva a retomar la relación con su padre.

El juego de relaciones familiares es uno de los puntos álgidos de la película. En un país donde el modelo familiar no se discute, Eastwood lo pone directamente contra las cuerdas. Mientras que Frankie está alejado de su hija por un motivo oculto y se le supone una ex mujer que o ha muerto o le ha abandonado, traza una relación paterno-filial con Fitzgerald.

${ }^{6}$ COMAS, Ángel. Clint Eastwood. Tras las huellas de Harry. T\&B Editores. Pág. 276 
“Tengo la misma edad que tendría este tipo, así que estoy representando mi edad. Cuando has vivido tantos años, entiendes los problemas familiares de la gente y te puedes figurar por qué la relación del personaje con su hija está deteriorada. Quizás fue un mal divorcio, quizás cuando él era joven estaba demasiado metido en el boxeo y no pasaba tiempo con ella. Has visto un montón de relaciones que se hacían y deshacían, en tu familia y en otras. Tienes muchas cosas a las que echar mano. Usas la imaginación. Y el dilema de conseguir al final un sentido para su vida y tener que volver a perderlo es lo más trágico". 7

Mientras que la boxeadora trata de agasajar a los suyos con los beneficios de sus peleas, sólo se encuentra desidia, desprecio e incluso desaires por parte de una madre estafadora a la seguridad social, una hermana sin oficio ni beneficio y un hermano ex presidiario.

Resulta magnífico como Eastwood desconstruye y reconstruye los lazos familiares de los protagonistas, acercando a Frankie y a Maggie hasta un punto cercano al romance. Mo Cushla será el leit motiv que construya ese paso más allá de ambos personajes hasta que, instantes antes de practicarle la eutanasia, Frankie le confiese que significa "mi amor, mi sangre."

Fuera de que resulte creíble que después de tanto tiempo, y cuando la película revela en los labios de Maggie que había salido en revistas y en televisión, que nadie le hubiera traducido esas dos palabras en gaélico, Eastwood le da un argumento más al espectador para que permanezca atento a la trama emocional. Construye su propio Mcguffin sin necesidad de enmarcarse en el género del suspense.

\footnotetext{
${ }^{7}$ SCHICKEL, Richard. Clint Eastwood: una retrospectiva. Editorial Blume. Pág. 254
} 
El punto amargo de la cinta lo constituye el abordaje de un tema tan complicado como la eutanasia. Eastwood deja que el relato sitúe esta última solución como la menos mala, la menos cruel. No se deja llevar por ideologías para edulcorar su posición ante el estado de la boxeadora y le aplica la adrenalina sabiendo que goza de la complicidad del espectador.

“La eutanasia, que cubre el tercio final de la película y escandalizó a los sectores más retrógrados de América, es realmente prodigiosa, pues casa a la perfección sensibilidad y técnica, y despliega una admirable sobriedad, dignamente conmovedora, a la hora de reflejar el sufrimiento que ambos personajes acusan a su respectiva manera." 8

Mucho tuvo que ver esta soberbia narrativa cinematográfica con la fotografía e iluminación utilizadas. Mientras que las escenas de boxeo son coloridas y gozan de una amplia cantidad y calidad cromáticas, las del hospital prácticamente se sumergen en un gris con suaves pinceladas verdes.

La iluminación resalta, como es casi ley en Eastwood, los dos lados del ser humano. En las escenas más íntimas, la mitad de la cara estará iluminada mientras que la otra mitad permanece en la oscuridad. Los relatos de las historias personas de Maggie, Eddie o el momento en el que Frankie se enfrenta a la eutanasia son acentuados con este recurso narrativo que llaman la atención del espectador sobre cuál de las mitades del personaje es la que está narrando.

La banda sonora vuelve a ser obra del propio Clint Eastwood. Como discípulo de Niehaus, el de Carmel utiliza un leit motiv basado en unas pocas notas a la guitarra para hacer transcurrir las escenas. Recurso que ya había utilizado, con similar éxito, en "Sin Perdón".

\footnotetext{
${ }^{8}$ AGUILAR, Carlos. Clint Eastwood. Cátedra, Signo e Imagen/Cineastas. Pág. 253
} 
Eastwood cada vez se siente más a gusto en su papel de autor holístico, dominando todos los campos que puede abarcar en la generación de una nueva obra cinematográfica. Sigue conservando a sus fieles trabajadores, pero se siente maduro en la toma de decisiones y en la funcionalidad de su criterio fílmico.

Dos temas más vuelven a ser recurrentes en esta película de Clint Eastwood. El primero es el del perdedor, tanto por Frankie Dunn como por Maggie Fitzgerald. Eastwood echa por tierra el sueño americano con dos personajes abocados a la eterna derrota y a sólo tener efímeros momentos de felicidad.

Como señaló el propio Eastwood: “Son personajes que están en la periferia de todo lo que conocemos. He visitado todos los viejos gimnasios de Los Ángeles para esta película, y allí ves tipos jóvenes tratando de llegar a algún sitio, persiguiendo un sueño que sabemos imposible. Y esta chica, la de la película, representa eso en la historia, alguien que ha tenido una educación limitada y que se resiste a ser una camarera toda la vida." 9

El segundo es la presencia fantasmagórica. Frankie Dunn nunca vuelve al gimnasio tras administrarle la eutanasia a su boxeadora. Se vuelve a ver el bar donde Frankie y Maggie toman tarta de limón a la vuelta de la visita a los familiares de ella.

Es cierto que Frankie comenta que no le importaría hacerse cargo del local, pero la última imagen de la película no resuelve esa duda. Se vuelve a ver el bar, pero dentro sólo se atisba a una camarera. No se sabe si Frankie ha adquirido el establecimiento, está de paso para huir a otro lado, o se para antes de quitarse la vida.

${ }^{9}$ COMAS, Ángel. Clint Eastwood. Tras las huellas de Harry. T\&B Editores. Pág. 275 
Eastwood deja abiertas todas las posibilidades transformando al entrenador en una suerte de fantasma que se introduce en la mente del espectador para que éste le proporcione el final que más desee. Así lo señaló el californiano: “Yo espero que el espectador participe en toda la película. Sabemos que Frankie es un extraño para su verdadera hija y que tiene una ex-mujer en alguna parte. Quizá hasta puede que tenga nietos, ¿quién sabe? Al final no sabemos dónde acaba. Vemos la cabaña donde ha tomado el pastel de limón, a través de la ventana. ¿Pero le vemos a él o no? Hay una camarera, pero eso no significa nada. Quizá no esté ahí. Quizá ha viajado a China. ¿Quién sabe? La audiencia debe pensar sobre esto, y si no es capaz de hacerlo, creo que es el espectador erróneo para esta película. La película representa cualquier cosa que tú creas que significa".10

\section{Sinopsis.}

La película arranca con un plano que nos introduce en un combate de boxeo. La voz en off nos presenta a Frankie Dunn. Maggie Fitzgerald también aparece en esta primera escena siguiendo el combate, pero en la lejanía de la zona alta de las gradas, por aquello de que es como un sueño para ella el llegar algún día a combatir como boxeadora profesional.

Una vez y nos cuenta a qué se había dedicado Frankie, y tras el combate, la película da paso a la primera conversación entre él y Maggie en la que ella le pide que le entrene pero él se niega. Sólo tiene un deseo: que su protegido, Willie, sea campeón.

La voz en off nos va dando más datos del Sr. Dunn y de sus ideas y pensamientos acerca del boxeo, al que ha dedicado toda su vida. "El boxeo es un acto antinatural,

${ }^{10}$ COMAS, Ángel. Clint Eastwood. Tras las huellas de Harry. T\&B Editores. Pág. 275 
en el boxeo todo va al revés. A veces la mejor manera de dar un puñetazo es retrocediendo".

Su religiosidad va a quedar patente en la siguiente escena donde le vemos rezando y pidiendo por su hija. Acto seguido sale de la Iglesia y se dirige al sacerdote porque se encuentra confuso acerca de ciertos términos religiosos. Se produce un diálogo donde Frankie busca y consigue exasperar al sacerdote, algo que volverá a repetirse con posterioridad en una pequeña escena en la que, de nuevo, vemos a Frankie salir de la celebración religiosa.

Otro plano aéreo nos presenta por primera vez el gimnasio que ahora regenta Frankie Dunn, el Hit Pit Gym, donde conocemos a 'Peligro', un chaval que, según Frankie, tiene algo muy importante que hay que tener en el boxeo, corazón. A través de él conocemos Eddie Scrap-Iron Dupris, ex boxeador, ciego de un ojo, y amigo de Frankie, que también trabaja allí.

Maggie vuelve a aparecer ya para no marcharse. Mientras está entrenando sola e insiste a Frankie para que le entrene, él vuelve a negarse. La voz en off también sirve para darnos a conocer algo mejor a Maggie. No tiene ni para comer, pero el poco dinero que gana trabajando en un bar de mala muerte lo ahorra para pagar el gimnasio en el que cada día entrena, el de Dunn.

Su rechazo hacia ella y el apoyo de Scrap provocan continuas discusiones entre ambos. Hasta que Scrap la ve entrenando a altas horas de la noche y decide darle algunos consejos para que mejore su golpeo al saco. Se establece un vínculo fuerte entre ambos, e incluso le regala un punchin, que ella dice que coge prestado hasta que se lo pueda comprar. Maggie le pide ahora a Scrap que si le puede entrenar, y éste acepta. 
La pasión de Maggie por el boxea también queda reflejada en su manera de aguantar las continuas bromas de sus compañeros de gimnasio por ser una chica.

Siempre centrado en su protegido Willie, Dunn empieza a volver la vista también hacia Maggie. En un perfecto plano-contraplano se produce la primera conversación seria entre ambos, en la que Dunn le da sus primeros consejos y termina regalándole su punchin.

Es el primer paso de una relación que empieza a florecer y que se va a terminar poniendo en marcha después de que en la siguiente escena, Willie, abandone a Dunn como entrenador antes justo del combate que le había conseguido para septiembre, dejándole por alguien que le asegure algo más que ganar el título. La música acompaña esta separación-despedida, que después le cuenta a Scrap. Éste le echa en cara el que haya sido su protegido porque al final se ha quedado sin combate por el título.

Varias escenas seguidas nos permiten conocer un poco mejor a Maggie y como su único interés es ahorrar dinero para invertirlo en material de boxeo. Mientras Dunn ve por televisión el combate de Willie (que termina ganando), la voz en off nos permite también conocerle y saber qué significa para él este deporte, con frases como "en el boxeo todo va al revés".

A partir de aquí Frankie y Maggie unirán sus vidas para siempre. Se produce el segundo encuentro importante entre ambos en el que ella resume en unas pocas frases lo desgraciada que es su vida. Él siente compasión. Será su entrenador y serán sus normas.

Aquí se produce ya la primera lección del viejo Dunn a Maggie, todo bajo la atenta mirada del causante de este encuentro, Scrap, y con un trabajo de plano-contraplano 
en el que Frankie aparece iluminado en contrapicado y Maggie en una cierta penumbra.

Una serie de planos fundidos, acompañados de la música que escucharemos durante toda la película, nos muestran la evolución de Maggie que aprovecha incluso su trabajo para practicar todo lo que Frankie le enseña. A ella y a nosotros, porque la voz en off nos introduce en el mundo del boxeo de una manera más técnica.

La siguiente escena nos vuelve a presentar a Frankie y Maggie en el gimnasio. Cuando todo parece ir bien y ella le comunica a Frankie que cree que está lista para combatir, aparece de nuevo la "imagen" de la hija del entrenador, Katie, y algo extraño le sucede a Frankie.

De repente le propone a Sally, "uno que pasaba por allí", que sea su manager y la abandona. Con él tendrá su primer combate, pero en la oscuridad de la distancia (como cuando Maggie sigue al principio el combate de Willie) Frankie Dunn no se lo pierde.

Al verla perder baja inmediatamente al ring para retomar las riendas del combate y darle instrucciones. Es el momento en que Frankie se autoafirma como su entrenador y, además, Maggie gana su primer combate. Sólo en estas escenas, Frankie aparecerá en un plano picado bajo el ring y es ella quien se está por encima, como la estrella del boxeo en la que espera convertirse. Aún así ella sigue teniendo sus dudas y le vuelve a preguntar que si le abandonará; Frankie responde: "Nunca".

La relación entre ambos se seguirá mostrando siempre con un Dunn superior en plano contrapicado, es el entrenador, el jefe, y Maggie en un plano picado como su pupila. Lo vemos incluso en algunos planos generales, como el siguiente en el que él la libera de los vendajes. 
Los combates para Maggie se empiezan a suceder. La voz en off nos dice que "no tardó en coger el ritmo". Era tal su evolución que a todas sus contrincantes las dejaba k.o. en el primer asalto y Frankie tuvo que pagar más para encontrarle adversarias decentes.

Un fundido entre un plano general y uno corto del entrenador nos muestra un avance en el tiempo en el que tomó la decisión de subirla de categoría y nos sitúa ya en su primer combate como tal. Le rompen la nariz, pero ella le pide a Frankie que se la recoloque porque cree que puede ganar y así ocurre.

Pero como consecuencia tiene que ir al hospital, será la primera vez, y también la primera vez que veamos a un arisco Frankie Dunn preocupado por su pupila. En el siguiente encuentro con el sacerdote conocemos que Frankie escribe a su hija, de la que no sabemos nada más, todas las semanas.

Aquella nariz rota de Maggie no fue impedimento ninguno para que siguiese compitiendo, y así llegaron las ofertas importantes para la boxeadora, como la de competir contra Billy, la "Osa Azul", por el título del peso Welter de la WBA, que Frankie rechazó, como otras tantas, que suponían enormes cantidades de dinero para ambos.

Maggie ha cumplido treinta y tres años. Lo sabemos por un encuentro que se produce entre ella y Scrap en el que éste le cuenta cómo fue su vida de boxeador, cómo conoció a Frankie, y cómo perdió el ojo por no parar en un combate. Es un anticipo de lo que va a ocurrir después.

Allí coincide con Micky Mac, el ahora manager de Willie, y cuando todos pensamos que ella también va a abandonar a Frankie por él, ocurre todo lo contrario. Una 
muestra de confianza devuelta que se produce justo a la mitad del film, cuando Frankie vuelve a recibir las cartas que le envía a su hija devueltas con el mismo sello: "devolver al remitente".

Pero esto sirve para que se produzca el auténtico giro en la película cuando Frankie visita a Maggie en su pequeño apartamento que, desde que le van las cosas mejor y Maggie ha empezado a ganar dinero con los combates, parece haber recobrado la luz.

Es también el momento en el que Frankie empieza a comportarse con Maggie como si fuera esa hija con la que nunca ha conseguido ponerse en contacto: "He cometido muchos errores en mi vida, no voy a permitir que tú hagas lo mismo". Este encuentro entre ambos supone también el comienzo del final, cuando Frankie le entrega una cinta de vídeo y le comunica que va a pelear por el título. La reacción de ella es darle un abrazo más propio de una hija a un padre.

Llegado el momento Frankie le regala a Maggie su primera bata de boxeadora en los instantes previos a su primer combate por el título, aunque aún no era el principal. Lleva una inscripción en gaélico en la espalda: Mo Cuishle (en español significa "mi amor, mi sangre"), nombre con el que la conocerán a partir de ahora en el mundo del boxeo.

Su adversaria es mejor que ella, más joven, más fuerte y con más experiencia, pero de nuevo vuelve a batirla después de escuchar las palabras de Frankie: “QQué vas a hacer para remediarlo?". Una victoria tras la que repite el salto a los brazos de su entrenador que se había producido anteriormente en el apartamento de ella. La cámara les rodea durante el abrazo mientras el público jalea su nombre, Mo Cuishle.

Después de una gira por una Europa (de la que sólo sabemos a través de la voz en off), Maggie vuelve a Estados Unidos y recibe otra oferta para luchar por el título. Se 
produce mientras Frankie y Maggie comparten una cena en la que está le comunica que le ha comprado una casa a su madre (él le dice: "eres una buena hija”).

Él la acompaña a visitarla y presencia una discusión entre ambas por el rechazo de su madre a aceptar esa casa para no perder las ayudas que le paga el gobierno. “¿Por qué no me diste el dinero? ¿Tenías que comprarme una casa?”. "No tenía que hacerlo mamá, pero es tuya. Si quieres el dinero, véndela". Su madre también la desprecia diciéndole que cuando le dice a la gente a qué se dedica (es boxeadora) se ríe. Esta situación deja preocupada a Maggie, pero también a Frankie.

La oscuridad, la penumbra, pero esta vez no la del gimnasio sino la de la noche mientras viajan en coche, vuelve a ser protagonista mientras Maggie le cuenta a Frankie más historias de su familia, de su padre. Murió. Y ahora, le dice, "sólo te tengo a ti, Frankie". Él le contesta: "sí, por lo menos hasta que encontremos un buen manager" (que por la recurrencia ya se ha convertido casi en una broma).

Mientras Maggie y Frankie se preparan para volar rumbo a Las Vegas al combate por el título, en el gimnasio se produce una escena, en la que está implicado Peligro, que se pude ver como el anticipo de lo que va a ocurrir después, y que ya había anticipado al comienzo de la película la voz en off en su presentación de este chico refiriéndose a algo que siempre decía Frankie: "A un boxeador que sólo tenga corazón sólo le espera una paliza".

Scrap es engañado por otro de los boxeadores del gimnasio para que acuda a arreglar una avería en el váter y aprovecha la coyuntura para organizar una pelea con Peligro. Cuando Scrap se da cuenta y llega para salvarle casi le habían destrozado la cara. Como venganza, el ex púgil le pide prestados los guantes a Peligro para pelar su combate número "110" (él ya había contado anteriormente que dejó de boxear después de 109 combates cuando perdió el ojo.) 
Ha llegado la hora del combate por el título. La música en la presentación de ambas contrincantes en su entrada al ring es muy diferente. A Mo Cuishle, la aspirante, le acompañan unos gaiteros y una iluminación casi directa. Su rival, la Osa Azul, la campeona mundial de los pesos wélter de la WBA, aparece con una música un tanto terrorífica y algo más en penumbra.

El combate es seguido en todas partes, por radio y televisión (lo vemos en planos intercalados de Scrap en su pequeño habitáculo) y el primer asalto no le sale nada bien a Maggie. Con la cara bastante dañada, Maggie consigue llegar al tercer asalto y, gracias a los consejos de Frankie, cuando parece que está a punto de ganar y se dirige ya hacía su esquina en medio de los gritos de ánimo del público, de imprevisto recibe un terrible puñetazo en la cara por el que cae inconsciente al suelo y se golpea brutalmente el cuello contra la silla que Frankie intenta apartar pero no llega a tiempo.

Silencio primero. Música fúnebre después y ralentización de la imagen para mostrarnos la escena en un plano aéreo que no hace presagiar nada bueno. Este lo combina con una imagen giratoria del techo del recinto en el que las luces nos evocan a las de un quirófano, y le sirve para fundir a negro y presentarnos el desenlace de la película.

Del fundido a negro vuelve con una imagen de Maggie que aparece en una cama de hospital sondada, y con otro fundido a negro lleva a cabo un pequeño avance en el tiempo. Aquí ya aparece Frankie, sentado en su cama y, aunque ella a duras penas puede hablar, intercambian unas frases.

De nuevo otro fundido a negro nos muestra la visita de Scrap al hospital. A través de una conversación con él Maggie nos cuenta que tiene la C1 y la C2 (vértebras 
cervicales) fracturadas y que, por lo tanto, se pasará el resto de su vida postrada en una cama, tetrapléjica.

Con Scrap ella también recuerda qué fue lo que falló aquel día: "No debí bajar la guardia, protegerme en todo momento". Era la frase con la que Frankie siempre le insistía que debía tener presente. La impotencia que inunda a Frankie le hace culpar de todo lo sucedido a Scrap porque, según él, fue quién le convenció para que entrenara a la chica.

Por ello también, intenta convencerse de que el problema de Maggie tiene solución y busca por todos los medios encontrarla. Frankie aparece de espaldas y totalmente a oscuras mientras hace llamadas a hospitales de toda América, y al fondo la luz que entra por una ventana es como la esperanza de ver la luz al final del túnel. Consiguió que la reconocieran, pero le dijeron que no había nada que hacer.

Dos meses después, Frankie puede mover a Maggie por primera vez. Mientras la moja con un paño humedecido descubre que tiene úlceras de cúbito porque no podía cambiar de posición.

Frankie decide llevarla de vuelta a casa para internarla en un centro de rehabilitación, donde la cuidaban muy bien. En el viaje en ambulancia desde Las Vegas ella le recuerda algo que le había dicho anteriormente: "Vamos en avión, volvemos en coche". No se había equivocado.

En la siguiente escena, dos únicos planos sirven para que veamos por primera vez a Frankie rezando en la Iglesia. Él era ya la única familia de Maggie y se pasaba todo el tiempo con ella en el centro de rehabilitación, porque de la familia biológica, que prometió ir a verla, supo más bien poco, o lo justo. 
Frankie averigua que llevaban una semana visitando Los Ángeles y cuando, de repente, aparecieron para visitarla intentó impedirlo. Acompañados de un negociante intentan que Maggie les firme unos documentos que autoricen a su madre a quedarse con todos los beneficios que ella ha conseguido, especialmente en los últimos años, gracias al boxeo.

Tiempo, por cierto, en el que nunca recibió el apoyo de los suyos. Lo hacen, además, como si intentaran ocultarle algo, aunque finalmente su madre le dice que es para proteger su dinero. Claro que su cuñado es más directo cuando confiesa que intentan evitar que ese dinero lo usen para gastos médicos ni del entierro.

Es ahí cuando Frankie vuelve a intervenir pero Maggie le dice que todo eso no es asunto suyo. Ella sola se encarga de echarles de allí con la misma insensibilidad que ellos la han tratado a ella durante toda esa visita, diciéndoles finalmente que, si no quieren perder su casa (la que ella les compró con todo su esfuerzo), no vuelvan a verla nunca más.

El tiempo pasa a través de un fundido con la siguiente imagen en la que vemos que las heridas (úlceras) de Maggie empeoran. Un médico le comunica que quizás vaya a perder una pierna. Esto provoca, por primera vez, las lágrimas de Frankie que, además, al llegar a su casa, se encuentra con otra de las cartas que le envió a su hija devuelta.

De nuevo unos planos fundidos muestran el paso del tiempo en el que Frankie espera en la habitación vacía de Maggie primero, y después con ella de nuevo, convaleciente tras salir de la operación en la que le han amputado una de sus piernas. Frankie aún alberga un halo de esperanza y mientras le da un beso le dice que todo saldrá bien. 
El tiempo continúa avanzando con Frankie siempre sentado a su lado en la cama. Se produce otra conversación relevante entre ambos en la que Maggie le pregunta qué significa Mo Cuishle (mi amor, mi sangre) y le dice que le recuerda a su papá.

La respuesta de él deja patente esa unión: “He pensado en comprarte una silla de ruedas. Quizás te gustaría volver a la universidad". Una unión que a partir de aquí nos deja entrever su final. Es cuando Maggie le cuenta a Frankie que no quiere continuar viviendo en una de sus intervenciones más largas.

Recuerda todo lo que ha vivido con el boxeo (nunca soñó que pasara), y cuenta que nació pesando poco más de un kilo y que su padre decía que luchó para entrar en este mundo y lucharía para salir de él (una especie de metáfora relacionada también con su incursión en el mundo del boxeo y cómo “salió” de él).

Pero no quiere luchar con Frankie para "marcharse" porque ahora tiene la oportunidad de hacerlo con el mejor recuerdo que le dejó su paso por el mundo del boxeo. El problema es que él se topa de frente con una lucha contra sus ideales religiosos que, en un principio, no le permiten llevar a cabo lo que ella le pide.

Su dilema le lleva incluso a hacerle una visita al sacerdote. Frankie le habla de ella y rompe a llorar. Ella quiere morir y él quiere quedarse con ella; es un pecado hacer lo que ella quiere, y si no lo hace la está matando. Pero el sacerdote es tajante y le dice que no lo haga.

Pero Maggie no iba a desistir de aquella decisión que ya tenía tomada. En plena noche mientras dormía en su casa, Frankie recibe una llamada del hospital. Se había mordido la lengua y casi se muere desangrada. Desde entonces la mantienen sedada para que no vuelva a repetirlo, y en esa situación se produce una nueva visita de Frankie. 
Una noche en el gimnasio intenta encontrar algo entre sus cosas. Allí se encuentra con Scrap que intenta disminuir su sentido de culpabilidad ("la maté", le dice Frankie). Scrap le da una lección de vida y la manera de reflejarlo en el plano enfatiza la intencionalidad, con un plano-contraplano en el que es Scrap, en esta ocasión, el que aparece en contrapicado, mirando a Frankie desde arriba. Éste parece haberse convencido con las palabras de Scrap.

En la siguiente escena sabemos qué era lo que había ido a buscar Frankie simplemente con su entrada al hospital en medio de la oscuridad y a hurtadillas para que no le vean las enfermeras que estaban de guardia. Iba a cumplir el deseo de Maggie. Antes le explica lo que va a hacer y le confiesa el significado de Mo Cuishle.

Una lágrima cae por la mejilla de Maggie, la primera vez que la vemos llorar, quizás sea de alegría porque se va a acabar su sufrimiento. Las imágenes siguientes son angustiosas. En un silencio absoluto, sólo con el sonido de las máquinas a las que Maggie permanecía enchufada, Frankie procede a desconectarle la respiración e inyectarle adrenalina. Maggie se duerme. Frankie la besa por última vez.

Scrap le esperó durante toda la noche en el gimnasio, pero Frankie nunca volvió. Por eso quiso escribirle una carta a su hija contándole quién había sido realmente su padre y deseando que estuviese en algún lugar donde pudiera encontrar la paz. Es espectador sí sabe dónde está Frankie.

En la última escena aparece un bar de carretera en el que vemos una sombra a través de la ventana. Allí había estado con Maggie y comido la mejor tarta de limón del mundo. 


\section{Conclusiones.}

Hábil y sin necesidad de artificios, Eastwood vuelve a plantear una jugada maestra sin necesidad de ofrecerle toda la información al receptor de su obra. "Ningún cineasta norteamericano ha retado de forma tan perseverante al público a aceptar finales tristes o ambiguos como él. Clint carece de cinismo y hace todo lo que puede para ofrecer películas que presentan un punto de vista de la vida honrado y nunca abiertamente ideológico, siempre tal y como él la ve."

El resultado, en global, es tan brillante como lo son las críticas de los autores que han estudiado a Eastwood en España y Estados Unidos: “Es un film riquísimo en lecturas múltiples que sorprende por la eficaz simplicidad de su puesta en escena y que reafirma a Eastwood - por si hubiese dudas - como autor con mayúsculas capaz de hacer una obra artística personal y contracorriente. La utilización de la fotografía, casi monocromática, sabe transmitir las especiales circunstancias de cada uno de los personajes y definir sus ideas sobre la amistad, la familia, el éxito o el fracaso, la religión, la eutanasia y, sobre todo, la soledad. Es una película epigonal en la que convergen puntos de vista sobre el individualismo, el mundo caótico exterior preservado tal vez por la paz del destartalado gimnasio o la negativa de Eastwood y Freeman a cambiar con el tiempo."

“'Million Dollar Baby' es la obra maestra de su prolífico autor, el cenit de su obra, de una especificidad cinematográfica tan pura que chirría dentro de la degradación sufrida por el lenguaje fílmico desde mediados de los años ochenta; una película extraordinaria por encima de los géneros y las épocas, dura y tierna por igual, a la par naturalista y abstracta, austera siempre y fantasmagórica a veces, personalísima pero nada elitista, coherente e impecable de principio a fin." 
“'Million Dollar Baby' es una mirada al sueño roto americano, al de las oportunidades de fama y gloria para cualquiera que se lo merezca y luche por ello, pero mucho más duro y menos autocomplaciente, aunque al final se percibe un rastro de esperanza. Y cuando Hillary le pide a Eastwood que le ayude a morir, ese católico atormentado y dubitativo, ese hombre de códigos, desde la cautela, toma una decisión que le lleva irremisiblemente a un lugar sin nombre; una decisión que le quiebra toda su vida."

\section{Bibliografía.}

AGUILAR, C. (2004): Clint Eastwood. Cátedra, Signo e Imagen/Cineastas.

BEARD, William (2000): Persistence of Double Vision: Essays on Clint Eastwood. University of Alberta Press.

CASAS, Q. (2003): Clint Eastwood: Avatares del ultimo cineasta clásico. Ediciones Jaguar.

COMAS, Á. (2002): Clint Eastwood. Tras las huellas de Harry. T\&B Editores.

SCHICKEL, R. (2005): Clint Eastwood: una retrospectiva. Editorial Blume.

THOMPSON, D. (2005): Billion Dollar Man. John Blake. 